\title{
Surface crack initiation mechanism for body centered cubic materials in the gigacycle fatigue domain
}

\author{
D. Wagner ${ }^{\mathrm{a}, *}$, C. Wang ${ }^{\mathrm{b}}$, Z. Huang $^{\mathrm{c}}$, C. Bathias ${ }^{\mathrm{a}}$ \\ a Université Paris Ouest Nanterre, LEME Laboratory, 50 rue de Sèvres, 92410 Ville d'Avray, France \\ ${ }^{\mathrm{b}}$ Sichuan University, Department of Mechanics and Engineering Science, Chengdu 610065, China \\ ' Sichuan University, School of Aeronautics and Astronautics, Chengdu 610065, China
}

Keywords:

Very High Cycle Fatigue (VHCF)

Armco iron

Crack initiation

Temperature recording

SEM observations

\begin{abstract}
A B S T R A C T
A BCC polycrystalline single phase Armco iron was tested in the Very High Cycle Fatigue (VHCF) régime using plate specimens and a load ratio of $R=-1$. Throughout testing until fracture, optical observations of the specimen surface (on one side) and temperature measurements and recordings (on the other specimen side) were performed. After failure, the fracture surfaces were observed via SEM. The macroscopic observations showed an early occurrence of Persistent Slips Bands (PSBs). The observations of fracture surfaces clearly revealed an initiation and propagation stage. In the initiation stage, which ranges from about 200 to $550 \mu \mathrm{m}$, the grain traces are visible with intergranular, transgranular and mixed fracture. The comparison with the thermal recordings leads to the conclusion that the crack initiation stage is completed near the end of the fatigue life. Interrupted tests show damage in the bulk specimen before the crack initiation.
\end{abstract}

\section{Introduction}

The French National Agency, ANR (Agence Nationale de la Recherche), supported a research project named DISFAT (Microplasticity and energy dissipation in very high cycle fatigue) from 2009 to 2014 in which Claude Bathias had been an active participant. The aim of the project was to develop a deeper understanding of microplasticity mechanisms of crack initiation for ductile materials in the VHCF regime. Microplasticity measurements were achieved via observations of slip markings on the specimen surface. We also carried out self-heating measurements which allows to specify the number of cycles at initiation and to obtain the dissipative sources. Three materials were studied: two FCC materials (pure copper and $\alpha$-brass) and one BCC polycrystalline single phase material (Armco iron with a small amount of carbon). Some results concerning pure copper and Armco iron have already been published $[1,19,21,29,30]$.

This paper is focused on the results obtained on the BCC single phase Armco iron, as reported in Chong Wang's doctoral dissertation [1], and amplified by some new results.

Whatever the fatigue régime (LCF, HCF or VHCF), the crack mechanism by fatigue includes microstructural changes which

\footnotetext{
* Corresponding author.

E-mail address: dwagner@u-paris10.fr (D. Wagner).
}

develop into damage stage, followed by a crack initiation stage (stage 1 ) and finally a crack propagation stage (stage 2 ). In the VHCF régime, if inclusions are present in the material, the crack initiation site moves from the surface to the interior with the formation of the so-called "fish eye" feature [2]. The materials without inclusions are called "type I" and those with inclusions "type II". The Armco iron investigated here exhibits type I behavior; all the crack initiation sites were observed on the specimen surface.

During the damage stage, microstructural changes on the specimen surface and beneath the surface occur. The to-and-fro dislocation displacements leads to a cyclic slip irreversibility as reported by Mughrabi et al. [3-6] measured by a factor denoted by $p$ and depending on the material. The cyclic slip irreversibility $p$ is defined as the fraction of microstructurally irreversible cyclic plastic strain in the total plastic strain $(0<p<1)$. When $p=1$, the dislocation slip is totally irreversible (LCF, HCF), whereas $p=0$ refers to a completely reversible slip. In the VHCF regime, the factor $p$ is between 0 and 1 . In order to accommodate the imposed cyclic strain, the dislocation structure must evolve.

In type I materials, in which crack initiation occurs on the surface, the accumulation of very small but irreversible slips over very large numbers of cycles results in Slip Markings (SM).

Extensive literature and results on BCC materials mainly pertain to the HCF regime [4-5,7-15]. The fatigue mechanism in the damage stage of polycrystalline BCC materials is governed by the 
transition temperature $T_{0}$. Below $T_{o}$, at low temperatures and low strains amplitudes, the screw dislocations are nearly immobile due to the increase of the thermal stress [4-14]. At low temperature, the activation of kinks will be absent leading to a much higher Peierls stress and less mobility. The dislocation gliding occurs mainly by the quasi-reversible gliding of edge dislocations (except on the specimen surface). Multiplication of dislocations is largely suppressed and there is little cyclic hardening. Above $T_{o}$, the gliding of screw dislocations increases. So, the behavior depends on the fatigue test temperature. Moreover, the temperature $T_{o}$ depends on the strain rate. This $T_{o}$ temperature is shifted to higher temperatures at higher strain rates. At a strain rate of $10^{-4} \mathrm{~s}^{-1}$, for $\alpha$-iron, $T_{o}$ lies around room temperature. In the VHCF domain, the strain rate is around $60-80 \mathrm{~s}^{-1}$ for $\alpha$-iron and $T_{o}$ will increase substantially. The dislocation behavior in the VHCF regime probably corresponds to the dislocation behavior observed below $T_{0}$, with almost no cyclic hardening. Another important point is the presence of interstitial carbon and nitrogen atoms in Armco iron. These interstitial atoms are obstacles to edge dislocation glide [4-16]. The dislocation velocities of edge and screw dislocations become similar those of FCC materials. Then, cross slip of screws becomes more active and hardening increases. Thus, in this case, clusters of high (edge) dislocation densities can develop to the extent of becoming unstable and breaking down locally to form PSBs in which a slip occurs more easily. At the same time, as the slip becomes more wavy, the local slip irreversibility increases. Then PSB in BCC materials may be observed. However, they do not usually have the classical wall/ladder structure seen in FCC metals. However, the cyclic strain localizes in narrow bands containing a dislocation cell structure, while the matrix structure becomes quite similar to the "vein" structure in FCC metals.

The damage stage leads to the initiation stage followed by the crack propagation stage. The distinction between the initial damage and the initiation stage is always difficult and somewhat ambiguous. Distinguishing between the crack initiation and the crack propagation stages is much clearer owing to the very different features which are easily observed and differentiated on the specimen surface. The transition from initiation to propagation has been operationally defined as being the point at which linear elastic fracture mechanics (LEFM) and the Paris law is applicable, independent of whether the material shows type I or type II features $[17,18]$. These models have been verified experimentally independent of the material type $[19,20]$. In the VHCF regime, more than $90 \%$ of the total life is consumed in the crack initiation stage.

In this paper, fatigue damage in Armco Iron was studied in the VHCF régime by recording the SM occurrence identified as PSB's and the temperature field on the specimen surface during testing. Interrupted tests were also performed to investigate the fracture damage in the bulk specimen. SEM observations of the PSBs and fracture surfaces were carried out to provide further information on damage accumulation.

\section{Experimental procedure}

Tests were performed using a piezoelectric fatigue machine designed by Bathias and co-workers [2]. To facilitate surface temperature measurements using an infra red (IR) camera, a newly designed $1 \mathrm{~mm}$ flat specimen was used for fatigue testing. The

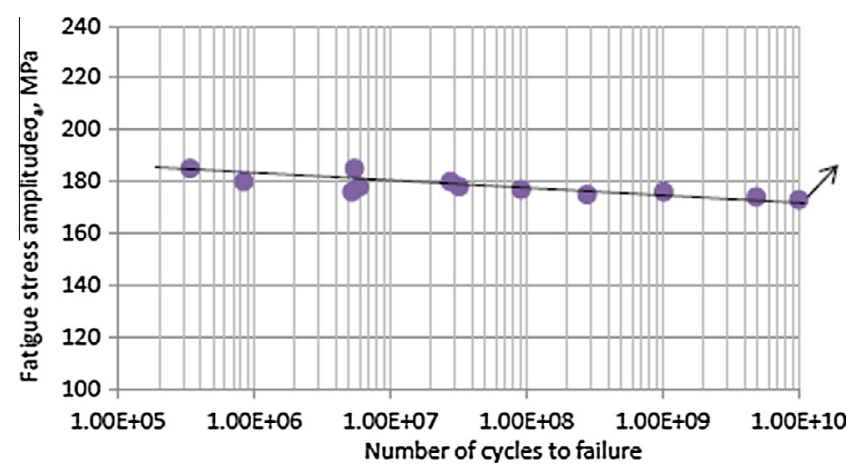

Fig. 1. $S / N$ curve for Armco iron.

resonance system was tuned to work at $20 \mathrm{kHz}$ and consisted of: (1) the specimen, (2) special attachments as appropriate and (3) the piezoelectric fatigue machine. The cyclic loading was tensioncompression at a stress ratio $R_{\sigma}=-1$. For some tests, before testing, both sides of the specimen surfaces were polished. One surface was electrolytically etched for optical observations, while the other side was covered by a thin layer of black paint to give a surface emissivity close to 1.

A CEDIP Orion infrared camera was used to continuously record the temperature during the test. The frequency of the camera was $50 \mathrm{~Hz}$ and the aperture time was $100 \mu \mathrm{s}$.

On the other side of the specimen, an in situ $320 \times$ optical microscope with was used to take real time images. In ultrasonic fatigue loading, the specimen centre is a strain node, and observation is only possible in a small area located at the specimen centre.

\section{Materials}

The material that was studied was a polycrystalline $\alpha$-iron whose chemical composition is given in Table 1 . The carbon content is $0.008 \mathrm{wt} \%$. The microstructure is ferrite with equiaxed grains. The ferrite grain size was between 10 and $40 \mu \mathrm{m}$ and the yield stress was $240 \mathrm{MPa}$.

\section{Results - discussion}

\section{1. $S-N$ curves}

The $S / N$ curve is shown in Fig. 1 and was obtained under condition of specimen cooling by a system located at the end of the horn. The specimen temperature $\left(45-65^{\circ} \mathrm{C}\right)$ was dependent on the loading amplitude.

\subsection{Observation of PSBs at the specimen surface}

Observations at the specimen surface were made during the tests (for 3 tests) by light microscope. These observations showed that irreversible slip bands (PSBs) were formed at the beginning of the fatigue loading $[1,21]$. These slip bands multiplied or grew within the same grain during subsequent cycle loading. New irreversible slip bands appeared in another near-by grain with a different orientation. Any given grain, either with or without slip

Table 1

Chemical composition of studied material (wt\%).

\begin{tabular}{|c|c|c|c|c|c|c|c|c|c|c|}
\hline$C$ & $\mathrm{P}$ & $\mathrm{Si}$ & $\mathrm{Mn}$ & $\mathrm{S}$ & $\mathrm{Cr}$ & $\mathrm{Ni}$ & Mo & $\mathrm{Cu}$ & Sn & $\mathrm{Fe}$ \\
\hline 0.008 & 0.007 & 0.005 & 0.048 & 0.003 & 0.015 & 0.014 & 0.009 & 0.001 & 0.002 & Balance \\
\hline
\end{tabular}



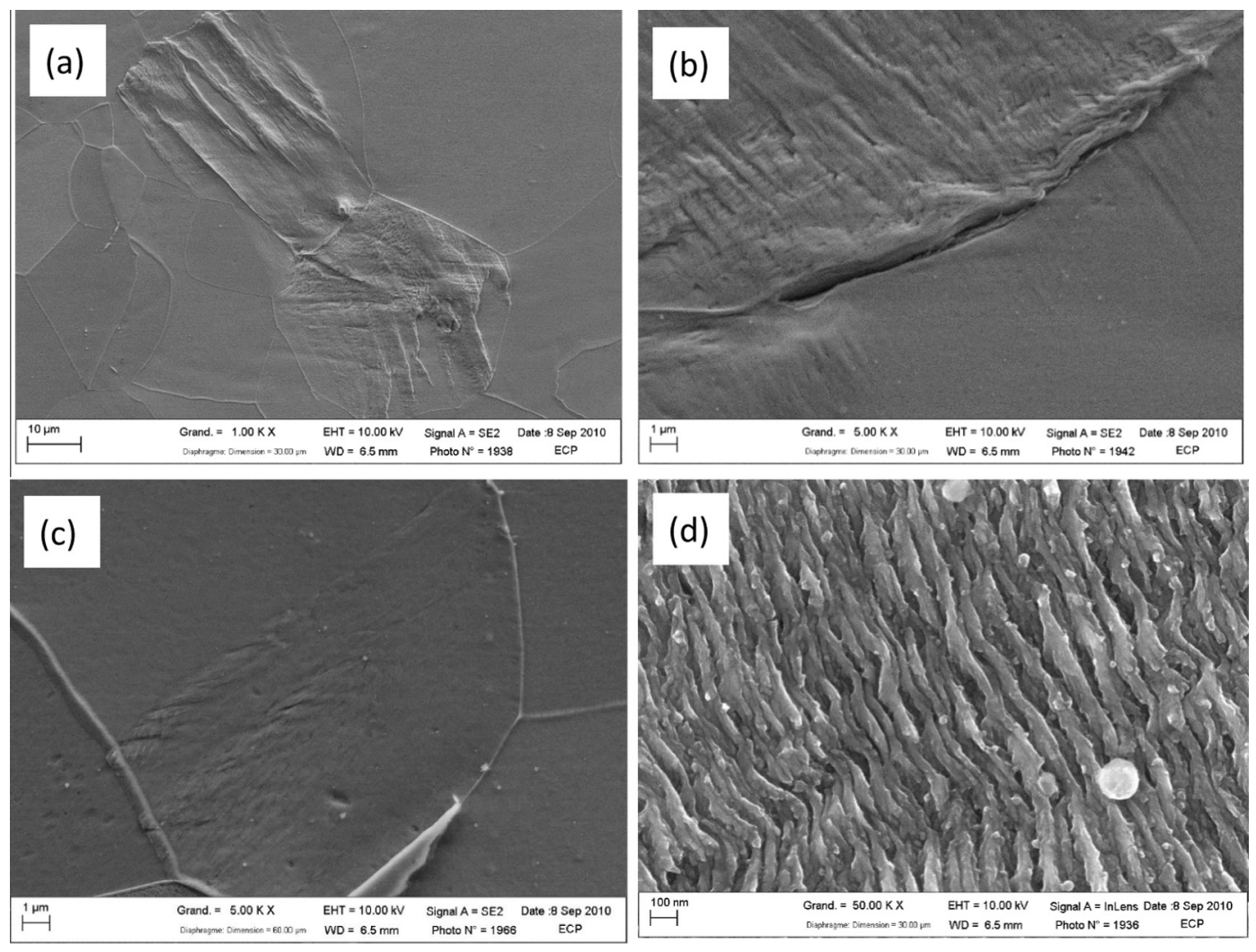

Fig. 2. Appearance of PSBs as observed via SEM.

band can develop new slip bands with continued cyclic loading. Most of the irreversible slip bands were formed before $10^{8}$ cycles. Only a slight evolution occurs by cyclic loading between $10^{8}$ and $10^{10}$ cycles.

Detailed observations of surface irreversible PSBs under via SEM are given in Fig. 2. The roughnesses of the PSBs are more or less pronounced depending on the crystallographic orientation of the grain (compare Fig. 2a, b, c). Sometimes a crack would appear in the grain boundary (Fig. 2b). Fig. 2d provides details of intrusions/extrusions which appeared on the surface grain and which had a mean width of $60 \mathrm{~nm}$

Hempel (1956, cited by Cazaud [22]) showed the occurrence of SM in Armco iron on the surface of plate specimens fatigued in bending. The higher the stress amplitude and the longer the test, the greater the number of SMs. SMs appeared very early. As expected, the lower the stress amplitude, the later the occurrence. For $N_{f}=5.6 \times 10^{5}$, SMs occured as early as $2.4 \times 10^{3}$ cycles (that is to say at $0.4 \%$ of the total life), and for $N_{f}=2.2 \times 10^{6}$ at $1.12 \times 10^{4}$ cycles $(0.51 \%$ of the total life).

Klesnil and Lukas [23] have studied the dislocation structure just beneath the surface in the bulk of Armco iron specimens fatigued in tension/compression at $83 \mathrm{~Hz}$ at two stress amplitudes $\left(22 \mathrm{kp} / \mathrm{mm}^{2}, \quad N_{f}=10^{6}\right.$ cycles; $24.5 \mathrm{kp} / \mathrm{mm}^{2}, N_{f}=5 \times 10^{4}$ cycles $)$. Their results confirm the early occurrence of SMs. The SM width is 1 to $2 \mu \mathrm{m}$. After removing a thin layer ( $2 \mu \mathrm{m}$ by electrolytic polishing, and etching), these SM remained visible with small stains, and the authors referred to this as a "bamboo structure". After removing a layer of 6-7 $\mu \mathrm{m}$, the SM were no longer visible.

The dislocation behavior of BCC metals differs from those of FCC metals by the slip plane asymmetry: the glide of screw dislocations occurs on different glide planes in forward and reverse directions (tension and compression) at low temperatures [4]. From Mughrabi et al. [4,5], "the fraction $\mathrm{f}$ of plastic strain accommodated by the glide of screw dislocations is in good approximation to the cyclic slip irreversibility $p$. The effect of the slip planes asymmetry leads to incompatible shape changes of neighboring grains which provoke intergranular cracking". The effect of the slip plane asymmetry which leads to incompatible shape changes of neighboring grains is responsible for the microcracks seen in the grain boundary, Fig. $2 \mathrm{~b}$.

\subsection{PSB modeling}

A specimen showing pronounced PSBs on three perpendicular surfaces, Fig. 3a, was investigated by SEM to gain a 3D understanding of mechanism of PSB formation [21]. The axial and cross surfaces were mechanically polished and etched with $4 \%$ Nital.

On the cross section, Fig. 3b, in one grain, equiaxed voids separated (or not) by a thin wall of matrix material (at the nanoscale) were observed. The voids were linearly distributed as shown by the yellow ${ }^{1}$ lines. The voids were equiaxed and were about $0.5 \mu \mathrm{m}$ in diameter. The linear dimension of the void rows was about 3 to $5 \mu \mathrm{m}$. The distance between void lines was approximately $2 \mu \mathrm{m}$. This feature looks similar to the "bamboo structure" described by Klesnil and Lukas [23]. Observation on the axial cutting surface, Fig. 3c, revealed longitudinal pronounced slots which were parallel in a given grain. A change in the orientation of the slots of about $90^{\circ}$ took place at a grain boundary. It seems reasonable to relate those slots to PSB formation on the original specimen surface. It was found that the slots were shallow. It seems these slots are like cylinders. The width of each individual slot is around $0.5 \mu \mathrm{m}$, the distance between parallel slots varied from $1 \mu \mathrm{m}$ to $3 \mu \mathrm{m}$ and the slot length is between $2 \mu \mathrm{m}$ and $10 \mu \mathrm{m}$. A 3D schematic figure of

\footnotetext{
${ }^{1}$ For interpretation of color in Figs. 3, 5 and 6, the reader is referred to the web
} version of this article. 

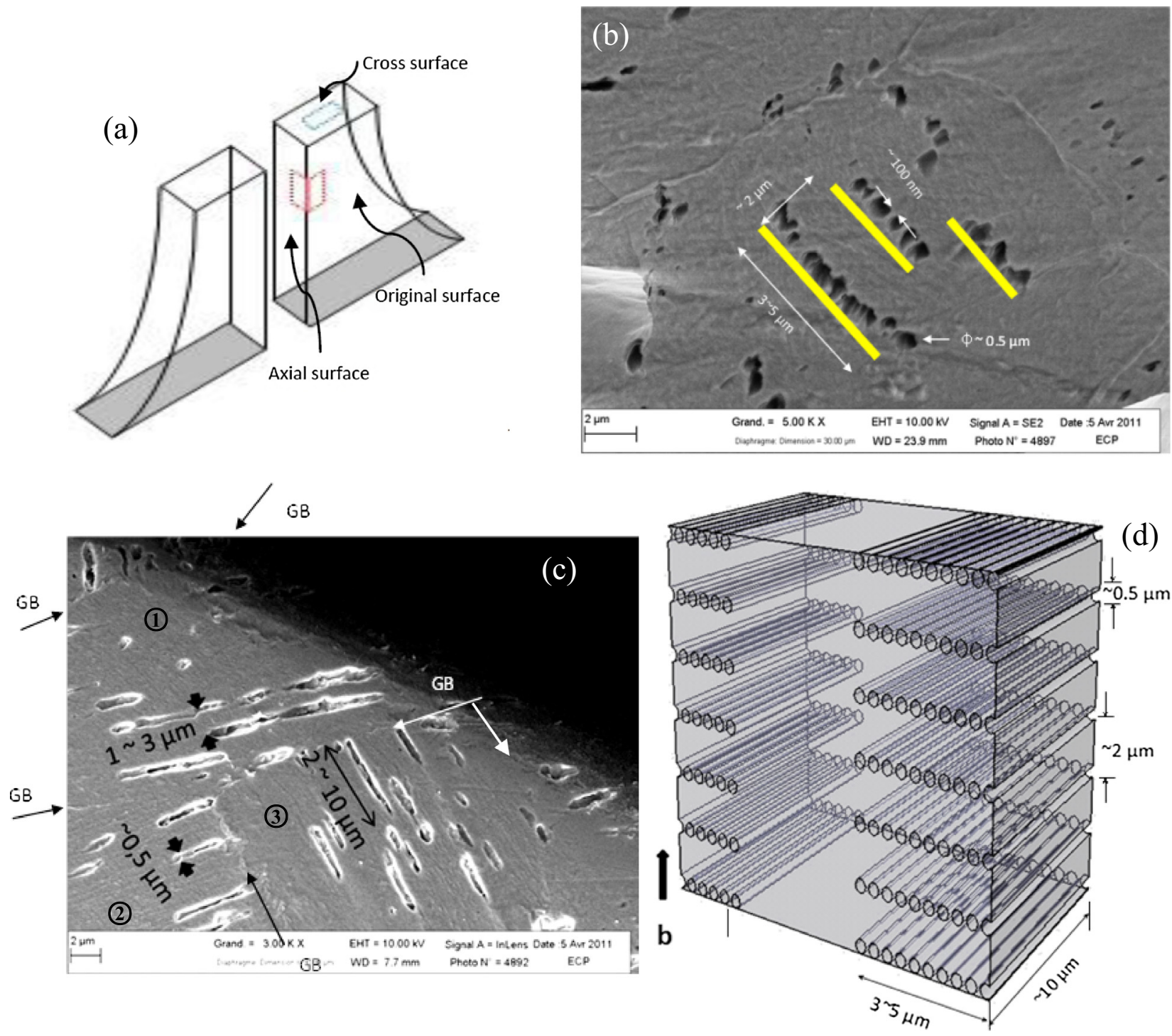

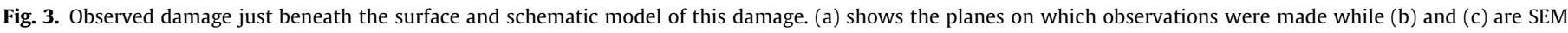
micrographs of defects observed on the cross sectional and axial surfaces respectively. (d) is a proposed schematic of the 3D defect structure.

the slots (pipes) and voids was developed using this information as shown in Fig. 3d. A presumed Burgers vector is also shown. This model could be used to illustrate the structure of the irreversible slip bands within one grain. The mechanism of forming this 3D structure is related to the gliding of dislocations. According to the grain orientation, the formation of extrusions/intrusions occurs on the specimen surface, Fig. 2a, in some cases. The TEM observations of Klesnil and Lukas [23] on thin foils taken just beneath the surface ( 1 to $2 \mu \mathrm{m}$ ) clearly show a dislocation structure with bands corresponding to the SM observed on the surface. These bands show regions which have both high and low dislocation densities. In BCC materials, the Transmission Electron Microscope (TEM) observations of the PSB structure do not show the classical wall/ladder structure seen in FCC materials. Never-the-less, with cycling, the strain localizes in narrow bands containing a dislocation cell structure while the matrix structure become quite similar to the vein structure in FCC metals. However, one case of PSBs with the ladder structure in the interior of a fatigued low-carbon steel has been reported ([24] cited by Mughrabi [25]). The PSB ladders revealed by the TEM micrograph are shown in Fig. 4. In the veins and in the walls, the local dislocation density is very high; these appear as black clusters. The distance between two walls in Fig. 4 is about $1.5 \mu \mathrm{m}$ and is in good agreement

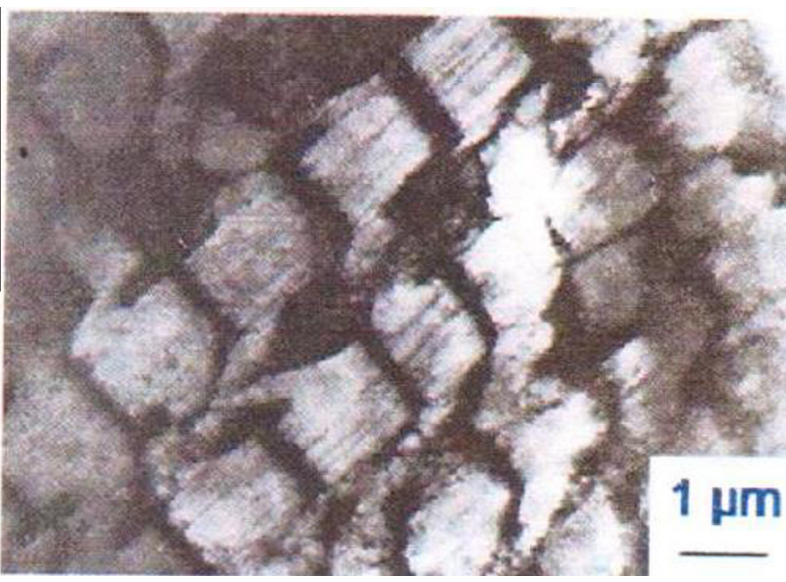

Fig. 4. TEM micrograph showing PSB ladders. After [24], cited by [25].

with the distance between longitudinal slots in the 3D model $(2 \mu \mathrm{m})$. The wall thickness in Fig. 4 is about $0.3 \mu \mathrm{m}$ and is in good agreement with the width of each individual slot $(0.5 \mu \mathrm{m})$. The longitudinal 
slots may be considered as the walls. With the preceding implications, the 3D model is consistent with the PSB structure observed by TEM in the HCF regime.

\subsection{Fracture surface observations}

The fracture surface and the polished specimen surface on which the temperature was recorded were examined via SEM. Fig. 5a and b shows the fracture surface of the specimen tested at $\sigma_{a}=178 \mathrm{MPa}$ and $N_{f}=3.255 \times 10^{7}$ cycles. Note that for all tests, the observations were qualitatively similar. Up to point 5 , the fracture surface was flat and corresponding to plane strain fatigue cracking.
Enlargement of the plane strain region, Fig. 5c, shows two main zones separated by the line at the point 3 . After point 3 , stage II of long crack propagation began with striations (Fig. 5e). At the beginning of stage II, the striations were not well established, whereas after point 3 (and the corresponding line), the striations were well defined. The mating surface of the specimen was examined and results are shown in Fig. $5 c$ and $d$. On the right side of Fig. $5 c$, the crack initiation site is located in the lower edge and the grain traces are clearly observed, Fig. $5 d$, whereas after the point 1, Fig. 5c, the fracture surface appearance changes (Fig. 5f). Those changes are attributed to the transition from the crack initiation stage (stage I) to a transition zone.
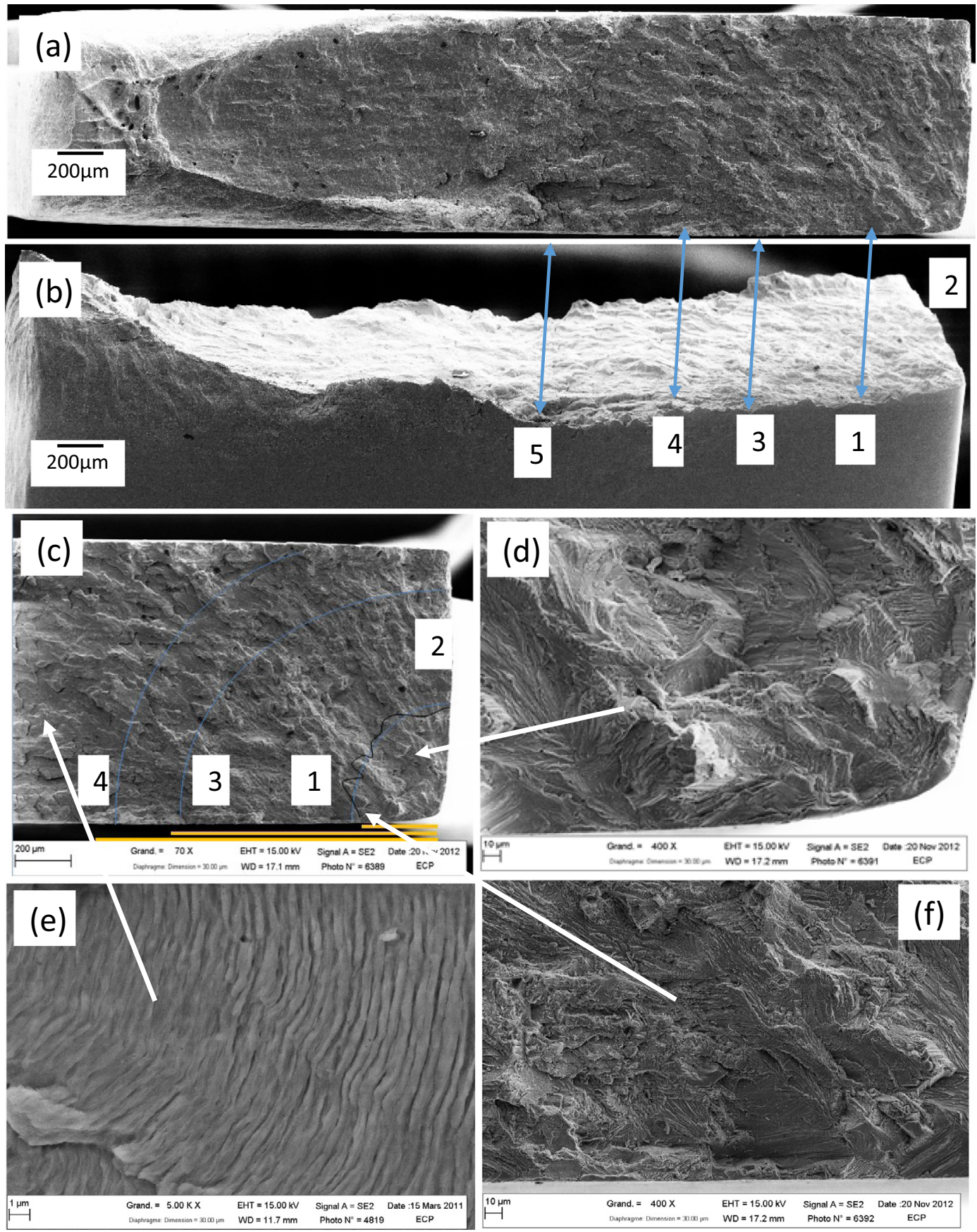

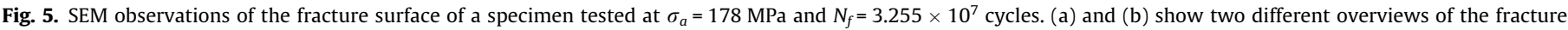
surface while (c) and (d) were taken from the lower part of the specimen and are at higher magnification. Details are discussed in the text. 

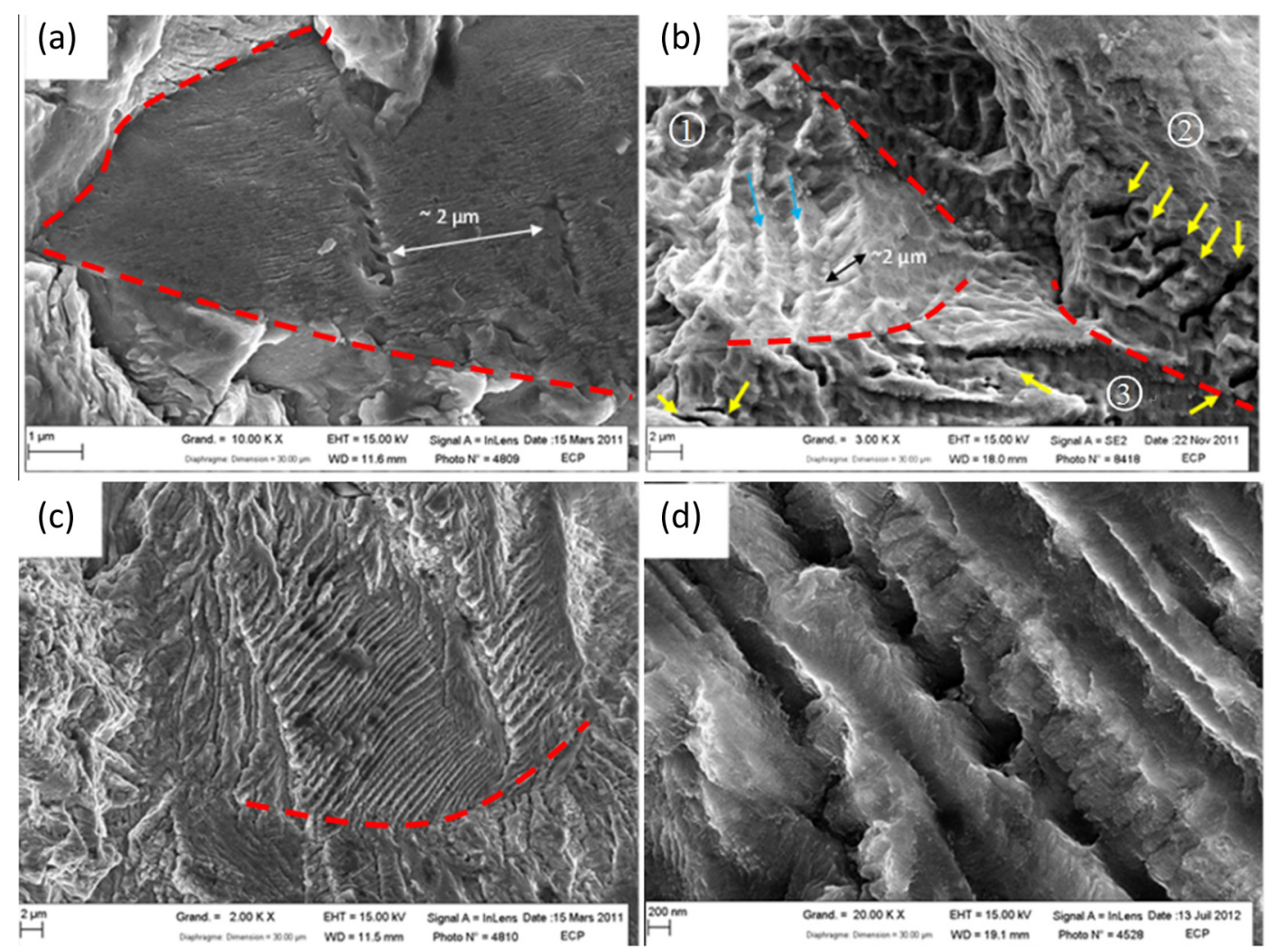

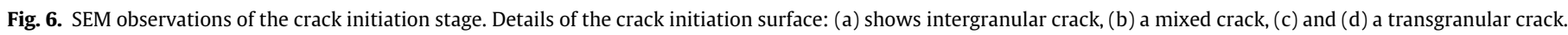

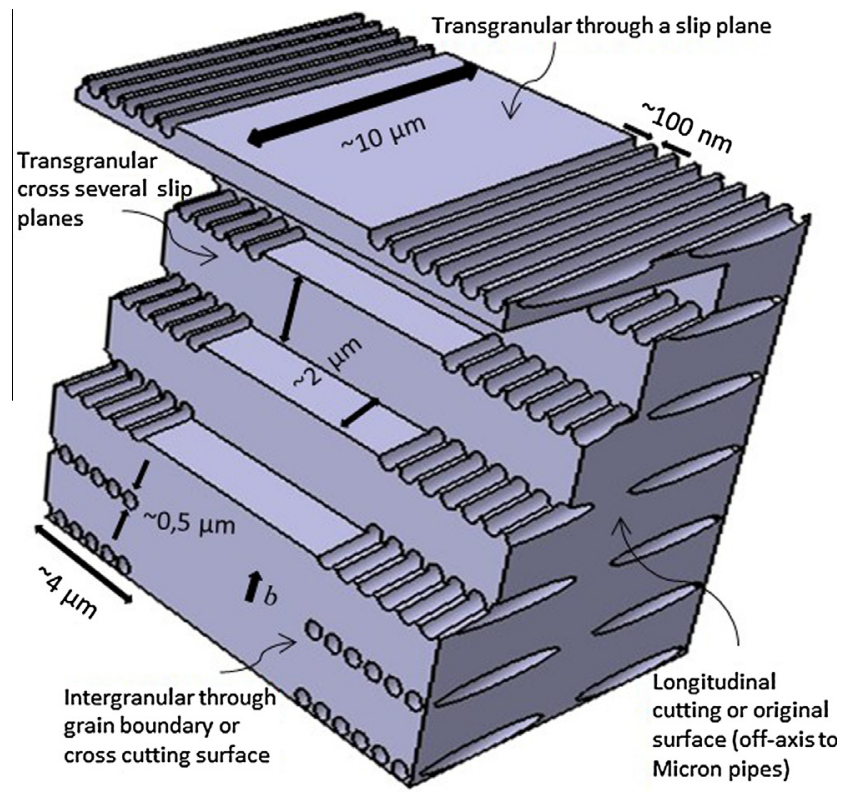

Fig. 7. Schematic model for the crack initiation stage.

In the initiation area, three types of patterns were found: (1) intergranular, (2) transgranular and (3) mixed. The intergranular pattern is seen in Fig. 6a. This intergranular crack surface appears not smooth, but presents a very fine linear structure on the grain surface which is believed to be related to slip planes intersection with the fracture surface. Moreover, two rows of voids about $2 \mu \mathrm{m}$ distant are visible. The type of mixed transgranular/intergranular crack surface is shown in Fig. $6 \mathrm{~b}$ in an area of grain

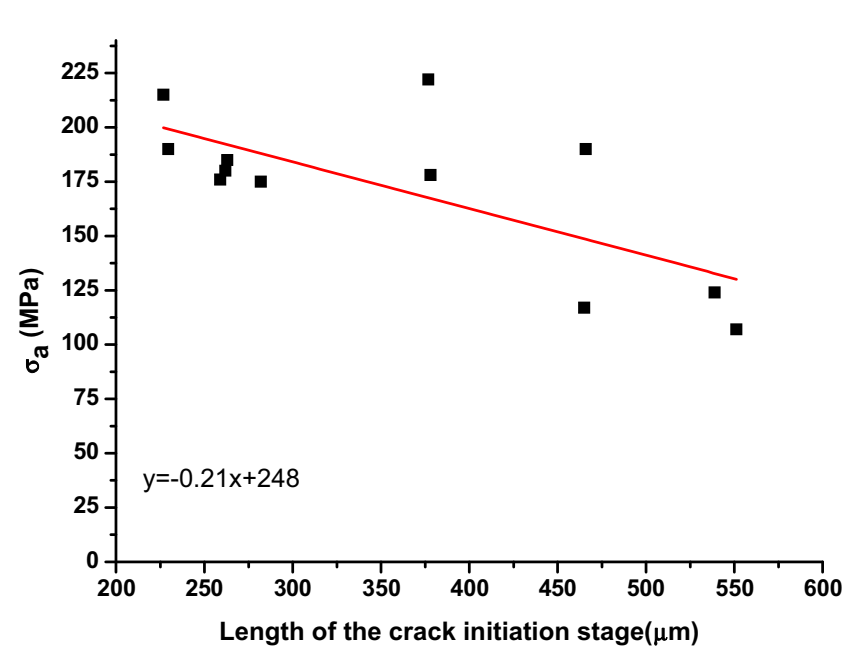

Fig. 8. Evolution of the crack initiation stage length with the stress amplitude. The line was obtained from a least squares fit.

intersections such as triple points. Mixed transgranular/intergranular fracture surface through grain 1 is present as a staircase (blue arrows) in Fig. 6b. The distance between two steps is about $2 \mu \mathrm{m}$. The yellow arrows on the middle right side of Fig. $6 \mathrm{~b}$ indicate patterns similar to those found in Fig. $6 \mathrm{a}$ in the intergranularly cracked grain. A transgranular crack surface is shown in Fig. 6c. In this case, the fracture surface is composed of longitudinal slots arranged side by side. The diameter of the slots is $0.5 \mu \mathrm{m}$ in average. A mechanistic approach at the crack initiation stage was provided based on the fracture surface pattern and the 3D model of Fig. 3d is suggested. An illustration of this fracture mechanism is 
schematically shown in Fig. 7. The staircase structure shown in Fig. 6 b, is probably a fracture occurring partially on the pipes, and crossing over the pipes just below. The distance between two steps is about $2 \mu \mathrm{m}$ which is in good agreement with the distance between two planes of the pipes. In the case of the transgranular pattern Fig. 6c, the crack path is entirely going through the pipes in the same slip plane. The characteristic dimension of a pipe diameter is about $0.5 \mu \mathrm{m}$. The line of hollows (separated by a distance of about $2 \mu \mathrm{m}$ ) present on the intergranular crack as in Fig. $6 a$ and on the cross section as in Fig. $6 \mathrm{~d}$ are probably the end of pipes at grain boundary (in good agreement with the distance between two neighbored pipe planes).

On Fig. 5c, consistent with all the SEM observations, the transition between stage I and the transition crack propagation zone on the fracture surface is shown. For the Armco iron tested on flat specimens, the crack initiation site was located either at a corner, as shown previously, or on the specimen side. For each specimen, the crack initiation site dimensions were determined and the stress intensity factors were calculated using the method previously reported [26]. Assuming that for $R=-1, \Delta K_{\mathrm{eff}} \approx K_{\mathrm{max}}$, the calculation of $\Delta K_{\text {eff }}$ at the transition between the initiation and transition propagation stage according to the fatigue stress amplitude and crack initiation length shows that this crack propagation threshold is constant and equals to $\sim 4 \mathrm{MPa} \sqrt{ } \mathrm{m}$ whatever the number of cycles. The model of Paris et al. [17] for crack growth in the case of a surface initiation is based on the Paris Hertzberg law [27]. Based on this working on crack growth and threshold, the threshold corner is set at $d a / d N=b$ and $\Delta K_{\mathrm{eff}} / E \sqrt{ } b=1$ ( $b$ is the Burgers vector and $E$ is Young Modulus). For steels, $E \sqrt{ } b=3.25 \mathrm{MPa} \sqrt{ } \mathrm{m}$ which is close to the value of $4 \mathrm{MPa} \sqrt{ } \mathrm{m}$ computed above.

In the HCF regime, the crack length at the end of the initiation stage varies as a function of fatigue life, from 2 to $3 \mu \mathrm{m}$ close to
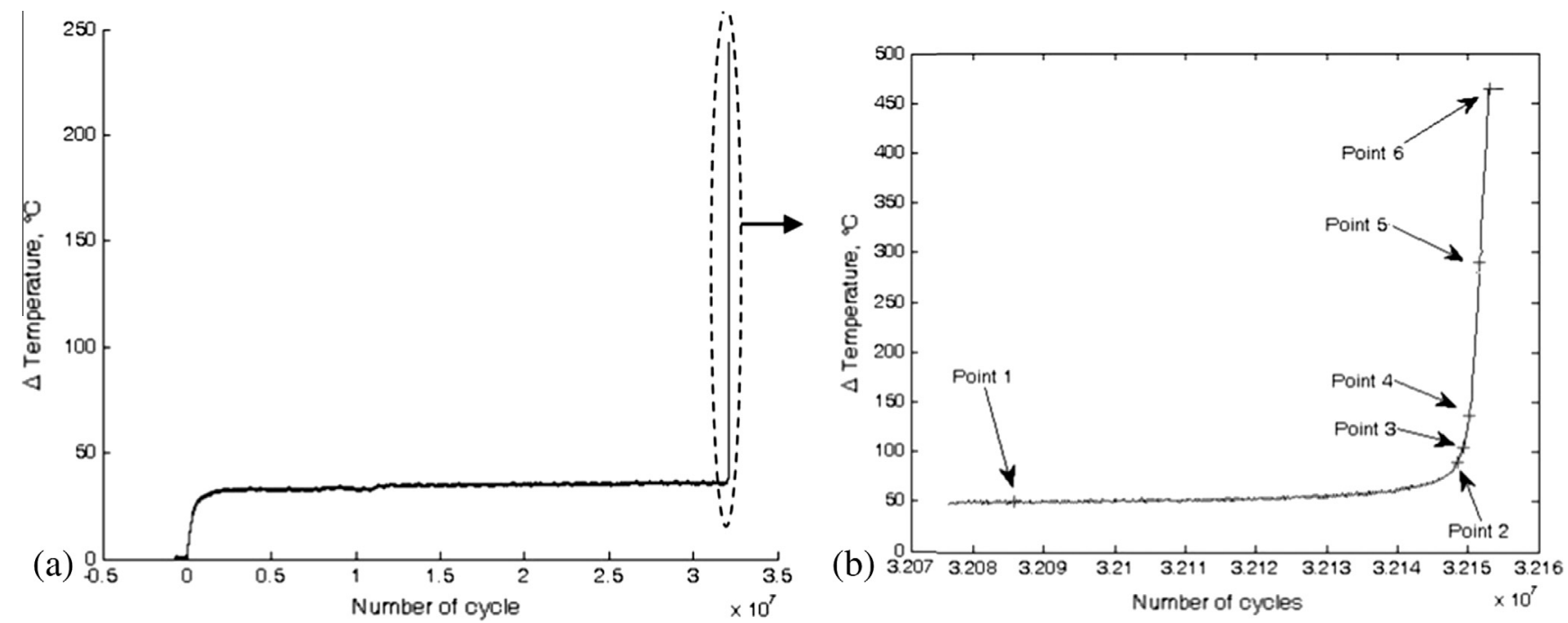

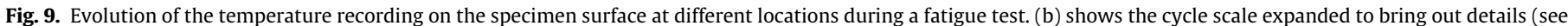
text).

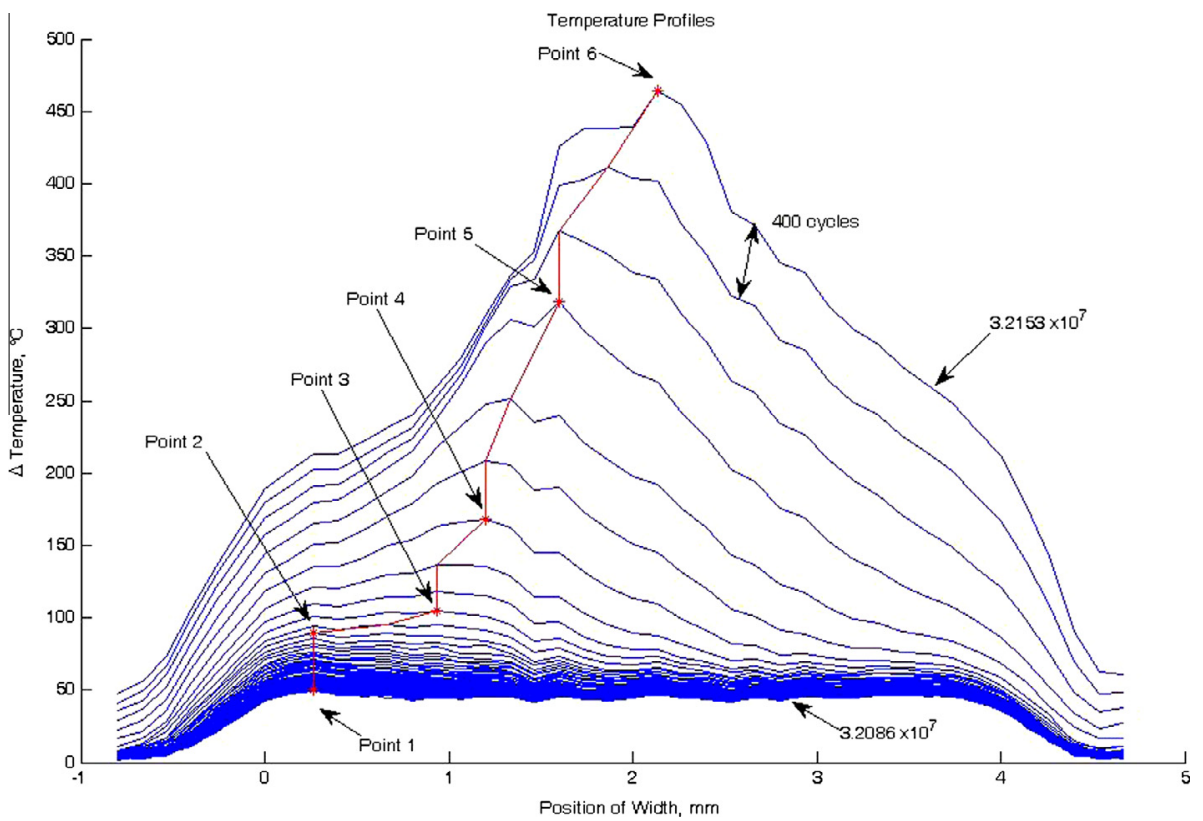

Fig. 10. Temperature profile along the specimen width. 
Table 2

Experimental conditions of the interrupted tests.

\begin{tabular}{|c|c|c|c|c|}
\hline Specimen & $\begin{array}{l}\text { Stress } \\
\text { amplitude }\end{array}$ & $\begin{array}{l}\text { Number of } \\
\text { cycles }\end{array}$ & Cooling & Damage \\
\hline FF3-15 & 176 & $1.41 \times 10^{9}$ & Yes & Yes \\
\hline FF3-18 & 131 & $1.3 \times 10^{9}$ & Yes & No \\
\hline FF4-04 & 146 & $1.4 \times 10^{9}$ & $\begin{array}{l}\text { Yes, but interrupted } \\
\text { during } 1 \mathrm{~h}\end{array}$ & Yes \\
\hline
\end{tabular}

the fatigue limit. In the LCF range, it varies from 0.1 to $1 \mu \mathrm{m}[6,28]$. In the test reported above in the VHCF domain, the crack initiation stage involved about 10 grains and measured about $300 \mu \mathrm{m}$. The formula for the stress intensity factor, is a function of the applied stress, the crack size, and the geometry. Typically, when $\sigma_{a}$ decreases, the crack length at the end of the initiation stage must increase to keep $\Delta K_{\text {transition }}$ constant. Here, in the VHCF domain, where $\sigma_{a}$ decreases from 200 to $100 \mathrm{MPa}$, the crack length at the end of the initiation stage goes from 200 to $550 \mu \mathrm{m}$ in the Armco iron, Fig. 8.

\subsection{Thermal results}

Independent of the frequency in the fatigue tests, the major part of the mechanical energy is converted into heat. It has been shown that the PSBs are the specific heat sources leading to an increase in the specimen temperature during the test [29]. The thermal results reported here have been extensively explained previously [19]. The main results needed for understanding and modeling of the crack initiation are reported here.

The specimen surface temperature is shown in Fig. 9a and b (which is an enlargement of the end of Fig. 9a). It corresponds to $\sigma_{a}=175 \mathrm{MPa}$ and $N_{f}=3.21 \times 10^{7}$ cycles. From these data, the temperature profile across the specimen width was taken from the last
168 frames captured by the IR camera before fracture (Fig. 10). The red line (Fig. 10) is the location where the temperature is maximum along the profile. The location where the temperature reaches its highest point along the profile, moves from the initiation stage (in the corner) to the final fracture. The IR camera resolution is such that the location of the crack tip at different times can be determined by the maximum temperature location. The study shows six points where the temperature had changed significantly. The corresponding number of cycles of these six points is reported in Fig. 9b. Each location where there is a large temperature change can be compared with the fractographic observations in Fig. 5c. The yellow lines in these figures are the locations of the points where the temperature maximum has an obvious inflection. Location 1 correspond to the end of the crack initiation stage on the side where the temperature field is recorded. After the occurrence of point 1 , the temperature does not change until it reaches point 2 as seen in Fig. 10. Probably, this time is consumed to coalesce the damage due to PSB between the specimen sides from point 1 to 2, (Fig. 5c).

The comparison between the fracture surface observations and the IR camera results demonstrates that more than $99 \%$ (in this test) of the total life is spent in the crack initiation stage.

\subsection{Specimen subsurface damage from interrupted tests}

For three specimens, fatigue tests were stopped before fracture and subsequently fractured under tensile loading. Table 2 gives the experimental conditions for these tests.

Before loading to failure, no crack was visible on the side surface of the specimens. After tensile tests, the fracture surfaces were observed by SEM. For the test at $\sigma_{a}=131 \mathrm{MPa}$, the overall surface was ductile. For the 2 others tests, the majority of the fracture surface is equally ductile, but some new features become
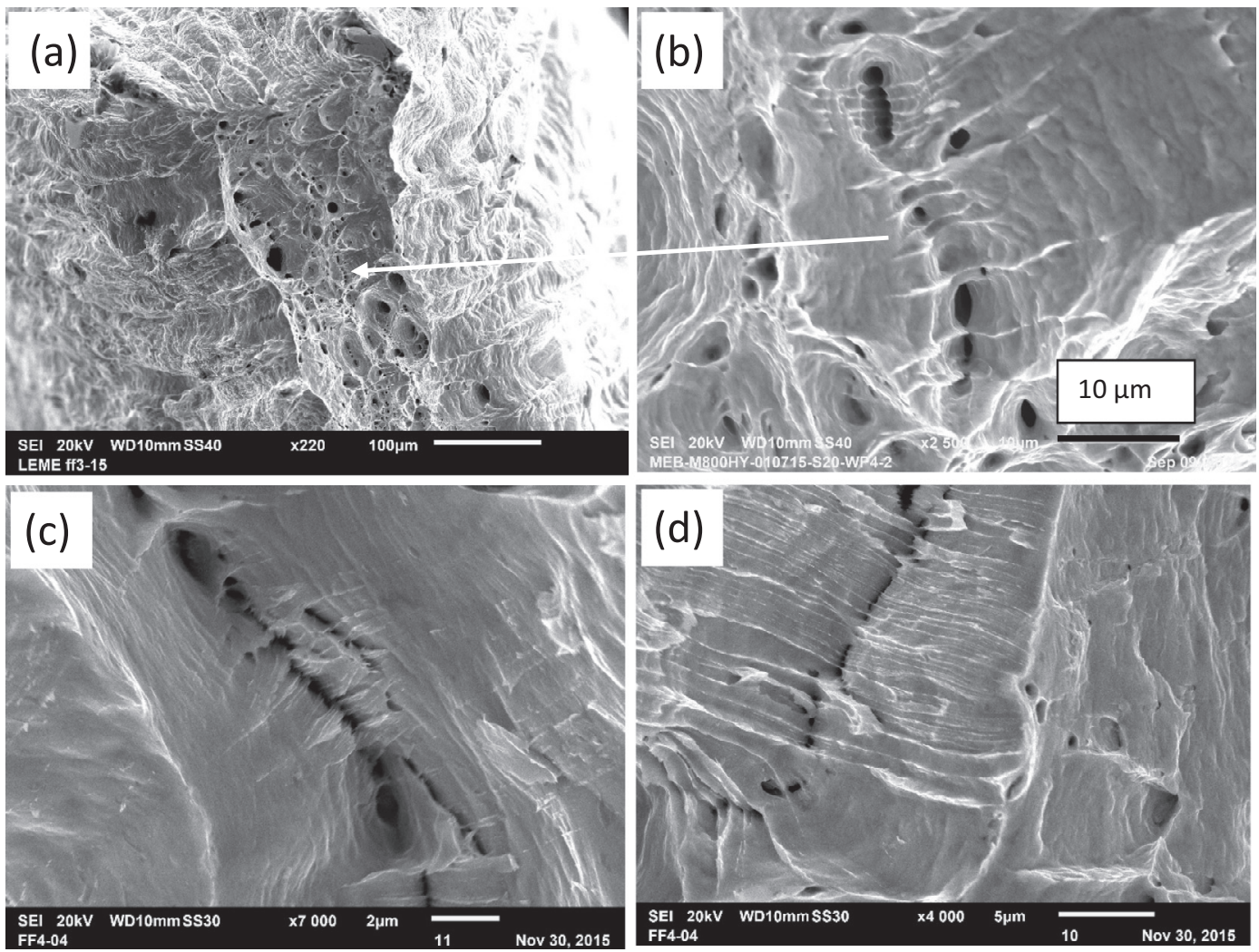

Fig. 11. Fracture surface observations of interrupted fatigue specimens fractured under monotonic tensile loading. ((a), (b): specimen FF3-15, (c), (d): specimen FF4-04). 
evident, Fig. 11. Fig. 11a shows part of the fracture surface at low magnification. Due to the reduction of area during tensile test, the specimen thickness is much reduced. On the side of the specimens slip bands were seen. On some grains on the fracture surface, (Fig. 11b) circular contiguous holes appear. On specimen FF4-04, where the cooling system was switched off for about $1 \mathrm{~h}$, the damage process is more pronounced, and near these holes a transgranular fracture surface is visible similar to that shown in Fig. 6c. These features appear to be the first damage in the specimen. In Fig. 11c, 2 lines of the end pipes (as in Fig. 3b) are visible. Due to the reduction of area, it is difficult to rigorously compare the characteristic lengths, but the sizes are of the same order of magnitude as discussed previously. The first damage appears as the occurrence of pipes (empty walls) in the matrix. For these thin specimens, the subsurface damage seen in the bulk specimen substantiates the thermal assumptions. Between points 1 and 2, Fig. 9b, the initiation stage starts and is due to the coalescence of all accumulated damage. Probably damage begins very early as the occurrence of PSBs on the specimen surface during fatigue tests.

When the stress is decreased (FF3-18, $\left.\sigma_{a}=131 \mathrm{MPa}\right)$, no damage is visible, even after $1.3 \times 10^{9}$ cycles, raising the question of whether there is a fatigue limit. More tests are necessary at different stresses, possibly requiring different specimen designs, to answer this question.

\section{Conclusions}

In the VHCF domain, a study of the surface crack initiation mechanism, using different observations and techniques for polycrystalline, single phase, BCC Armco leads to the following conclusions:

- The macroscopic observations on the specimen surface show, as in the HCF regime, an early occurrence of SMs or PSBs for this Armco iron containing $0.008 \%$ of carbon.

- The microscopic observations just beneath the PSB provides a basis to propose a schematic 3D model of these PSBs. The model appears to be in good agreement with the dislocation arrangements seen in PSBs in the HCF regime in literature.

- Fracture surface observations by SEM clearly reveals crack initiation and propagation stages. The initiation crack length is longer than in the HCF régime and spreads over many grains. A mechanism from the 3D model of PSB is proposed to explain the fractures surface pattern in the initiation stage.

- Temperature measurements on the specimen side during testing and correlated with the fracture surface observations, reveal that the crack initiation consumes the vast majority of the life (i.e. $\sim 90 \%$ ).

- In agreement with the early occurrence of PSB even in the VHCF domain, the interrupted tests for this Armco iron type I material suggest the existence of damage even in subsurface before the number of cycles at initiation.

- At a stress amplitude $25 \%$ below the conventional fatigue limit, no damage occurs.

\section{Acknowledgements}

The authors would like to thank Prof. Stephen Antolovich and Prof. Haël Mughrabi for many useful discussions.
This research was supported by the grant from the project of Microplasticity and energy dissipation in very high cycle Fatigue (DISFAT, project No. ANR-09-BLAN-0025-09), which funded by the National Agency of Research, France (ANR).

\section{References}

[1] Wang C. Microplasticité et dissipation en fatigue à très grand nombre de cycles du fer et de l'acier. Thèse de doctorat de l'Université Paris Ouest soutenue le 7 juin 2013.

[2] Bathias C, Paris PC. Gigacycle fatigue in mechanical practice. New York: Marcel Dekker; 2004.

[3] Mughrabi H. Specific features and mechanisms of fatigue in the ultrahigh-cycle regime. Int J Fatigue 2006;28:1501-8.

[4] Mughrabi H. Cyclic slips irreversibilities and the evolution of the fatigue damage. Met Mater Trans 2009;40A:1257-79.

[5] Mughrabi H. Cyclic slip irreversibility and fatigue life: a microstructural-based analysis. Acta Mater 2012.

[6] Mughrabi H. Microstructural fatigue mechanisms: cyclic slip irreversibility, crack initiation, non-linear elastic damage analysis. Int J Fatigue 2013;57:2-8.

[7] Antolovich SD, Armstrong RW. Plastic strain localization in metals: origins and consequences. Prog Mater Sci 2014;59:1-160.

[8] Mughrabi H, Ackerman F, Herz K, Persistent slipbands in fatigued facecentered and body-centered cubic metals STP 675; 1979. p. 69-105.

[9] Mughrabi H. Microscopic mechanisms of metal fatigue. In: Haasen P, Gerald V, editors. Proc of 5th ICSMA, vol. 3. Pergamon Press; 1980. p. 1615-38.

[10] Mughrabi H. Dislocations in fatigue. Dislocations and properties of real materials, vol. 323. London: The Institute of Metals; 1985. p. 244-62.

[11] Suresh S. Fatigue of materials. 2nd ed. Berlin: Cambridge University Press; 1998.

[12] Mughrabi H, Herz K, Stark X. The effect of Strain-rate on the cyclic deformation properties of $\alpha$-iron single crystals. Acta Mater 1976;24:659-68.

[13] Mughrabi H, Wüthrich. Asymmetry of slip and shape changes during cyclic deformation of $\alpha$-iron single crystals. Philos Mag 1976;33(6):963-84.

[14] Mughrabi H, Herz K, Stark X. Cyclic deformation and fatigue behavior of $\alpha$-iron mono- and polycrystals. Int J Fract 1981;17(2):193-220.

[15] Sommer C, Mughrabi H, Lochner D. Influence of temperature and carbon content on the cyclic deformation and fatigue behaviour of $\alpha$-iron. Part 1 . Cyclic deformation and stress behaviour. Acta Mater 1998:46(5):1527-36.

[16] Huang Z, Ranc N, Wagner D. Dislocations gliding study by IR thermography in C-Mn steels with different solute content in the gigacycle fatigue domain. Key Eng Mater 2016;664:177-87.

[17] Marines-Garcia I, Paris PC, Tada H, Bathias C. Fatigue crack growth from small to long cracks in VHCF with surface initiations. Int J Fatigue 2007;29:2072-8.

[18] Marines-Garcia I, Paris PC, Tada H, Bathias C. Fatigue crack growth from small to long cracks in very high cycle fatigue with surface and internal "fish eyes" failures for ferritic-pearlitic low carbon steels SAE 8620. Mater Sci Eng A 2007;468-470:120-8.

[19] Wang C, Wagner D, Bathias C. Study of fatigue crack mechanism on an Armco iron in the gigacycle fatigue by temperature recording and microstructural observations. Proc int cong on fracture, 2013, Beijing 2013.

[20] Ranc N, Wagner D, Paris PC. Study of thermal effects associated with crack propagation during very high cycle fatigue. Acta Mater 2008;56:4012-21.

[21] Wang C, Wang QY, Wagner D, Huang Z, Bathias C. Very High Cycle Fatigue crack initiation mechanism according 3D micron abreast pipes model of PSB on $\alpha$-ferrite. FFEMS 2015;38:1-11.

[22] Cazaud R, Pomey G, Rabbe P, Janssen Ch. La fatigue des métaux. Ed. Dunod, Paris; 1969.

[23] Klesnil M, Lukas P. Dislocation arrangement in the surface layer of $\alpha$-iron grains during cyclic loading. J Iron Steel Inst 1965:1043-8.

[24] Pohl K, Mayr P, Macherauch E. In: Sih GC, Provan JW, editors. Defects, fracture and fatigue. The Hague/Boston/London: Martinus Nijhoff Publishers; 1983. p. 147.

[25] Mughrabi H. Cyclic deformation and Fatigue of different steels: fundamentals and some examples of applications. Proc of the 2 nd int symposium on steel science, 2009, Kyoto, Japan 2009.

[26] Wang C, Wagner D, Bathias C. Investigations on the fatigue crack propagation threshold in very high cycle fatigue. Adv Mater Res 2014;891-892:357-62.

[27] Hertzberg RW, Vinci RP, Hertzberg JL, Fatigue crack propagation in deformation and fracture mechanics engineering materials, 5th ed. J. Wiley; 2013.

[28] Ibrahim MFE, Miller KJ. Determination of crack initiation life. FFEMS 1980;2:351-60.

[29] Wang C, Blanche A, Wagner D, Chrysochoos A, Bathias C. Dissipative and microstructural effects associated with fatigue crack initiation on an Armco iron. Int J Fatigue 2014;58:152-7.

[30] Phung NL, Favier V, Ranc N, Vales F, Mughrabi H. Very high cycle fatigue of copper: evolution, morphology and locations of surface slips marking. Int J Fatigue 2014;63:68-77. 